\title{
An analysis of malpractice litigation related to the management of brain aneurysms
}

\author{
Raghav Gupta, Christoph J. Griessenauer, MD, Justin M. Moore, MD, PhD, Nimer Adeeb, MD, \\ Apar S. Patel, MD, MPH, Christopher S. Ogilvy, MD, and Ajith J. Thomas, MD
}

\begin{abstract}
Division of Neurosurgery, Department of Surgery, Beth Israel Deaconess Medical Center, Harvard Medical School, Boston, Massachusetts
\end{abstract}

\begin{abstract}
OBJECTIVE Given the highly complex and demanding clinical environment in which neurosurgeons operate, the probability of facing a medical malpractice claim is high. Recent emphasis on tort reform within the political sphere has brought this issue to the forefront of medical literature. Despite the widespread fear of litigation in the medical community, few studies have provided an analysis of malpractice litigation in the field. Here, the authors attempt to delineate the medicolegal factors that impel plaintiffs to file medical malpractice claims related to the management of brain aneurysms, and to better characterize the nature of these lawsuits.
\end{abstract}

METHODS The online legal database WestLawNext was searched to find all medical malpractice cases related to brain aneurysms across a 30 -year period. All state and federal jury verdicts and settlements relevant to the search criterion were considered.

RESULTS Sixty-six cases were obtained. The average age of the patient was 46.7 years. Seventy-one percent were female. The cases were distributed across 16 states. The jury found in favor of the plaintiff in $40.9 \%$ of cases, with a mean payout of $\$ 8,765,405$, and in favor of the defendant in $28.8 \%$ of the cases. A failure to diagnose and/or a failure to treat in a timely manner were the 2 most commonly alleged causes of malpractice. Settlements, which were reached in $25.8 \%$ of the cases, had a mean payout of $\$ 1,818,250$. Neurosurgeons accounted for $6.7 \%$ of all defendants.

CONCLUSIONS Unlike other medical specialties, a majority of the verdicts were not in the defendant's favor. The mean payouts were nearly 5 -fold less in cases in which a settlement was reached, as opposed to a summary judgment. Neurosurgeons accounted for a small percentage of all codefendants.

https://thejns.org/doi/abs/10.3171/2016.9.JNS161124

KEY WORDS medical malpractice; brain aneurysm; neurosurgery; 1985-2015; vascular disorders

$\mathrm{T}$ HE widespread perception in the medical community is that medical practitioners face a constant threat of malpractice litigation. This has led to a documented shift in clinical behavior among practicing physicians, giving rise to the practice of defensive medicine. ${ }^{15}$ It is estimated that this behavior alone contributes to a $\$ 60$ billion increase in the nearly $\$ 3$ trillion annual health care expenditure in the US. ${ }^{13}$ Therefore, positive defensive medicine, or the practice of administering superfluous tests, medications, and services as a preventative measure, has inherent economic and health implications. Negative defensive medicine, or the practice of abstaining from performing potentially higher-risk procedures for fear of facing a malpractice claim, has ethical consequences. ${ }^{14}$ Defensive medicine has been touted as a deli- cate balancing act, given its potential benefit in instances of uncertainty within the clinical setting, and its misuse within the health care system as a buffer against malpractice litigation. ${ }^{11}$

A retrospective study published in the New England Journal of Medicine in 2011 reported that $19.1 \%$ of neurosurgeons faced a malpractice claim annually, which is the highest among all medical specialties. ${ }^{9}$ A recent report found that of the neurosurgeons who had been surveyed in the US, more than $80 \%$ reported practicing positive defensive medicine, with a strong correlation between their state's liability environment and their clinical behavior. ${ }^{13}$ This behavior is further complicated by standard fee-forservice medical environments, which incentivize volume over quality, contingency fee arrangements with medical 
malpractice attorneys, and large malpractice insurance premiums for physicians. ${ }^{12,20}$ Given the increasing emphasis on tort reform within the political sphere, and an increase in the rate at which brain aneurysms have been detected over the past several decades ${ }^{1,5}$ we sought to characterize the reasons for malpractice litigation related to the treatment of these lesions in the US, over a 30-year period. In addition, we hoped to better characterize the nature of these cases to better inform practicing physicians about the ways in which they can minimize these occurrences.

\section{Methods}

Institutional review board approval was waived for the purposes of this study. WestLawNext (Thomson Reuters, New York), an online legal research service, was used to search for state and federal jury verdicts and settlements (court decisions) related to brain aneurysms and malpractice litigation between January 1, 1985, and December 31, 2015. WestLawNext is a comprehensive collection of 40,000 databases containing legal documents including court dockets, jury verdicts and settlements, case law analyses, and trial court orders, all compiled by attorneyeditors. Local cases and claims that were dismissed prior to proceeding to trial, or that were settled out of court, are not available on the database. Boolean-based searches are supported by the platform, and were performed to determine a keyword combination that yielded the greatest number of case files related to the management of brain aneurysms. A search that incorporated the keywords "brain aneurysm" and "medical malpractice" met this criterion. Only cases pertinent to the diagnosis and/or treatment of cerebral aneurysms were considered.

Duplicate case files and files related to litigation involving other medical conditions were excluded from the analysis (Fig. 1). The age and sex of the patient and/or the plaintiff, the state and county in which the trial proceeded, factors that impelled litigation, the number and specialties of codefendants, award payouts, jury verdicts, and initial patient symptomatologies were recorded for each of the cases. Finally, the number of malpractice cases per actively licensed physician within each state (obtained via a recent census ${ }^{24}$ in 2014) were calculated.

\section{Results}

\section{Selection of Relevant Cases}

Ninety-one cases related to brain aneurysms and medical malpractice over a 30-year period (1985-2015) were obtained. Thirteen cases involving the treatment of other conditions were discarded, and 12 duplicate case files were removed. The remaining 66 cases were used for further analysis (Fig. 1).

\section{Patient Demographic Data}

The average age of the affected patient and/or plaintiff was 46.7 years (Table 1). Forty-seven (71.2\%) patients were female.

\section{Geographic Distribution and Legal Jurisdiction}

Cases were distributed across 16 states: California (15; $22.7 \%)$, New York $(8 ; 12.1 \%)$, and Florida $(7 ; 10.6 \%)$ had the highest number of malpractice cases related to brain aneurysms. Conversely, only 1 (1.5\%) case each from Alabama, Kansas, Mississippi, and Minnesota were found. The highest number of cases per capita (i.e., per actively licensed physician) were observed in Washington (0.000189), Connecticut (0.000120), and Missouri (0.000116), in descending order (Table 2). Sixty-five of the cases were decided at the state level (98.5\%), with 1 case falling under federal jurisdiction (1.5\%). Of the 26 states that passed tort reform laws that limit payments for noneconomic damages, in 10 medical malpractice suits were filed within the study pe-

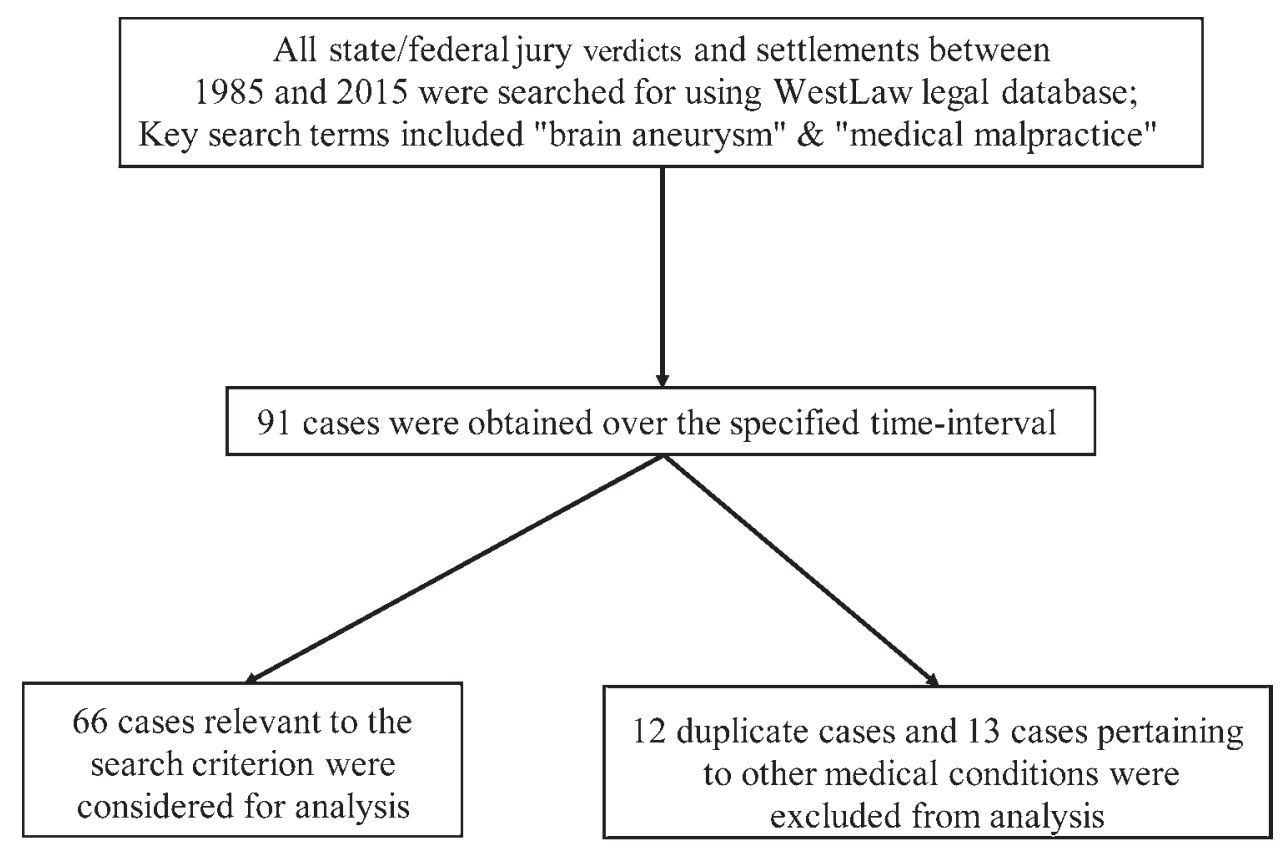

FIG. 1. Flow chart illustrating the search strategy. 
TABLE 1. Malpractice litigation related to brain aneurysms from 1985 to 2015

\begin{tabular}{|c|c|}
\hline Variable & Value (\%) \\
\hline \multicolumn{2}{|l|}{ Demographic data } \\
\hline \multicolumn{2}{|l|}{ Sex of patient } \\
\hline Male & $19(28.8)$ \\
\hline Female & $47(71.2)$ \\
\hline Mean age in yrs* & 46.7 \\
\hline \multicolumn{2}{|l|}{ Geographic distribution } \\
\hline Alabama & $1(1.5)$ \\
\hline California & $15(22.7)$ \\
\hline Connecticut & $2(3.0)$ \\
\hline Florida & $7(10.6)$ \\
\hline Illinois & $5(7.6)$ \\
\hline Kansas & $1(1.5)$ \\
\hline Massachusetts & $2(3.0)$ \\
\hline Minnesota & $1(1.5)$ \\
\hline Mississippi & $1(1.5)$ \\
\hline Missouri & $3(4.5)$ \\
\hline New Jersey & $2(3.0)$ \\
\hline New York & $8(12.1)$ \\
\hline Ohio & $5(7.6)$ \\
\hline Pennsylvania & $3(4.5)$ \\
\hline Texas & $5(7.6)$ \\
\hline Washington & $5(7.6)$ \\
\hline \multicolumn{2}{|l|}{ Medicolegal analysis } \\
\hline \multicolumn{2}{|l|}{ Case jurisdiction } \\
\hline State & $65(98.5)$ \\
\hline Federal & $1(1.5)$ \\
\hline \multicolumn{2}{|l|}{ Reasons for litigation } \\
\hline Lack of informed consent & $3(4.5)$ \\
\hline Failure to diagnose & $41(62.1)$ \\
\hline Failure to treat & $39(59.1)$ \\
\hline Failure to refer/order diagnostic tests & $28(42.4)$ \\
\hline Misinterpretation of test(s) & $10(15.1)$ \\
\hline Unnecessary surgery & $2(3.0)$ \\
\hline Procedural error & $11(16.7)$ \\
\hline Open surgery & $7(63.6)$ \\
\hline Endovascular surgery & $4(36.4)$ \\
\hline Death & $29(43.9)$ \\
\hline \multicolumn{2}{|l|}{ Mean payouts } \\
\hline Range & $\$ 100,000-\$ 43,000,000$ \\
\hline Plaintiff & $\$ 8,765,405 \dagger$ \\
\hline Settlement & $\$ 1,818,250 \ddagger$ \\
\hline Mixed & $\$ 25,550,000 \ddagger$ \\
\hline
\end{tabular}

riod (Table 1 and Fig. 2). ${ }^{2}$ Of the 16 states in which medical malpractice cases were identified, 13 (81.3\%) had instituted joint and several liability reform.
TABLE 2. Per capita malpractice cases per state

\begin{tabular}{lc}
\hline $\begin{array}{l}\text { Geographic } \\
\text { Distribution }\end{array}$ & $\begin{array}{c}\text { No. of Malpractice Cases/No. of } \\
\text { Actively Licensed Physicians per State }\end{array}$ \\
\hline Alabama & 0.000062 \\
\hline California & 0.000105 \\
\hline Connecticut & 0.000120 \\
\hline Florida & 0.000099 \\
\hline Illinois & 0.000114 \\
\hline Kansas & 0.000111 \\
\hline Massachusetts & 0.000059 \\
\hline Minnesota & 0.000046 \\
\hline Mississippi & 0.000100 \\
\hline Missouri & 0.000116 \\
\hline New Jersey & 0.000056 \\
\hline New York & 0.000087 \\
\hline Ohio & 0.000111 \\
\hline Pennsylvania & 0.000054 \\
\hline Texas & 0.000069 \\
\hline Washington & 0.000189 \\
\hline
\end{tabular}

\section{Type of Malpractice Alleged}

A failure to diagnose in a timely manner (41 cases; $62.1 \%$ ) or to treat in a timely manner (39 cases; 59.1\%) were the 2 most commonly cited reasons for litigation. Failure to order appropriate testing and/or refer a patient to the necessary specialist was described in $28(42.4 \%)$ of the cases. Misinterpretation of diagnostic tests was cited as a factor in $10(15.1 \%)$ of the cases. Technical procedural errors were cited as a factor in $11(16.7 \%)$ of the cases. Open surgical procedures accounted for 7 (63.6\%) of these, and endovascular procedures were implicated in the remaining $4(36.4 \%)$. These procedures included craniotomy for microsurgical clipping of aneurysms, microsurgical clipping of aneurysms (separate from craniotomy), ventriculostomies, digital subtraction angiograms, and coil embolization of aneurysms. Injury of cerebral arteries with a catheter was cited in 3 cases, 2 of which were treated endovascularly and the third with open microsurgery. A failure to adequately administer heparin to a patient prior to coil placement, a failure to adequately manage blood pressure during aneurysm clipping, and a failure to recognize the appropriate anatomical surgical approach were among the procedural errors cited. Imaging procedures, including $\mathrm{CT}, \mathrm{MR}$, and radiographic imaging, were implicated concurrently with failure to diagnose and/or misinterpretation of a test in 7 other cases. The patient and/or plaintiff died in $29(43.9 \%)$ cases (Table 1$)$.

\section{Specialties of Codefendants}

Among the 66 cases, a total of 188 codefendants were represented. Physicians were implicated in $56 \%$ of these cases, with neurosurgeons accounting for $12 \%$ of all specialists and $6.7 \%$ of all defendants. Emergency medicine, family medicine, and internal medicine practitioners accounted for a combined $20 \%$ of all physicians implicat- 


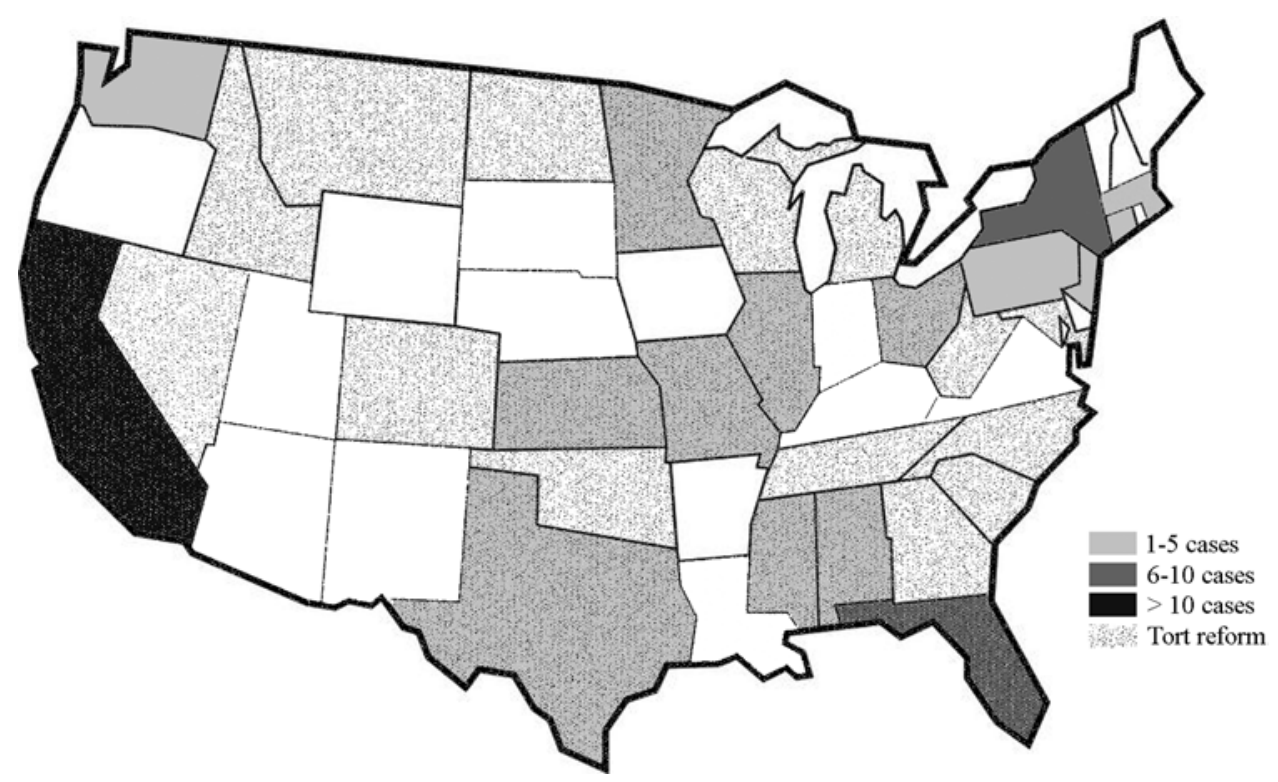

FIG. 2. Map illustrating the geographic distribution of the number of malpractice cases related to brain aneurysms in the US from 1985 to 2015. No cases were observed in either Hawaii or Alaska. Superimposed on these data are the states (these include Alaska and Hawaii, which are not shown) that have passed tort reform laws that limit the value of payouts related to noneconomic damages.

ed in these cases. Radiologists accounted for $5.6 \%$ of all defendants and $10 \%$ of all physicians. Hospitals, medical clinics, and medical centers were codefendants in $23 \%$ of the cases (Fig. 3B).

\section{Jury Verdicts and Payments}

The jury found in favor of the plaintiff in 27 (40.9\%) of the cases (Fig. 3A), with a mean payment value of $\$ 8,765,405$ (SD $\$ 13,218,704$; range $\$ 100,000$ $\$ 43,000,000)$. In $17(25.8 \%)$ of the cases, a settlement was reached, with a value of $\$ 1,818,250$ (SD $\$ 1,326,207$; range $\$ 150,000-\$ 4,350,000)$. A mixed verdict was reached in $2(3.0 \%)$ cases, resulting in a payment of $\$ 25,550,000$, in 1 of these cases (Table 1). The jury found in favor of the defendant in $19(28.8 \%)$ cases. A hung jury resulted in a mistrial in a single case.

\section{Chronological Distribution of Cases}

An analysis of the frequency with which medical malpractice claims related to brain aneurysms were filed between 1985 and 2015 found an upward trend when assessed in 5-year intervals. The greatest number of claims was found between 2006 and 2010, after which point the frequency of claims decreased dramatically (Fig. 4).

\section{Discussion}

More than $10 \%$ of a physician's career is spent addressing unresolved malpractice claims. ${ }^{4}$ These can significantly influence the reputation of a physician ${ }^{18}$ as well as his or her decision making in the clinical setting. Several studies have tried to better delineate the factors that contribute to malpractice claims within different medical subspe-
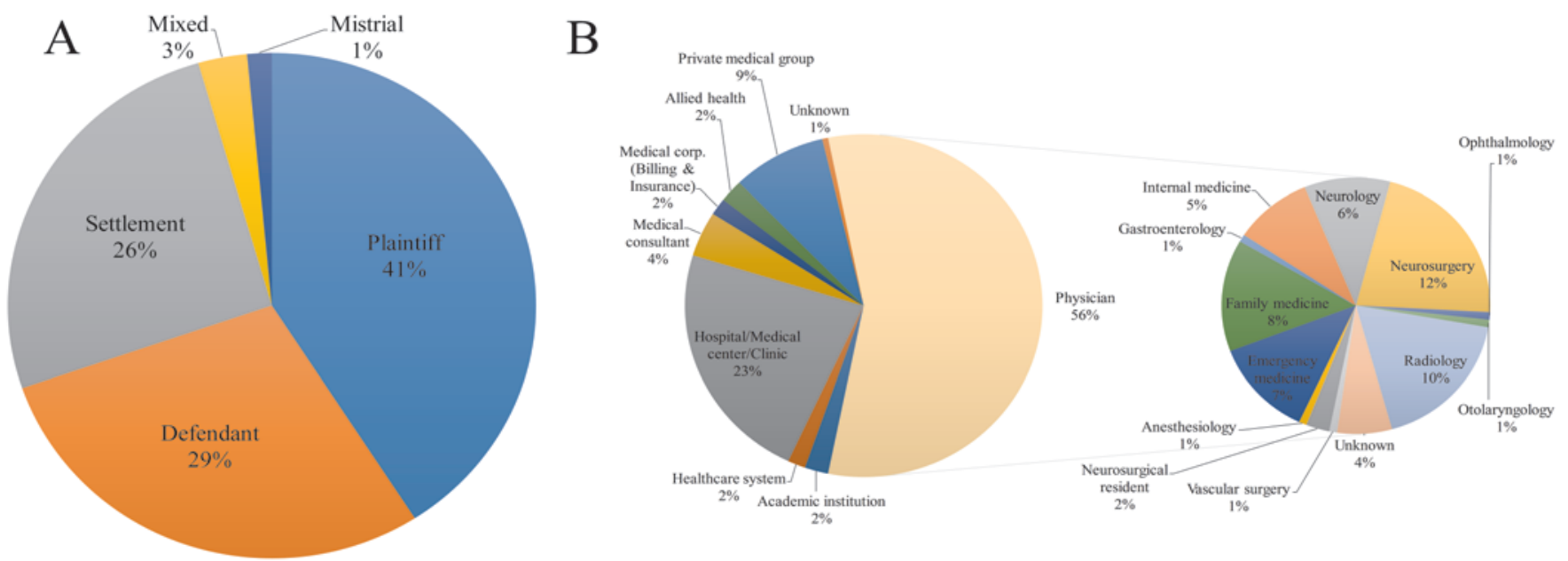

FIG. 3. Pie charts showing a summary of the jury verdicts (A), and a breakdown of the specialties of the codefendants implicated in these cases, with further delineation of the subspecialties of the physicians involved (B). Figure is available in color online only. 
cialties, including otolaryngology, radiology, and plastic surgery. ${ }^{16-18,23}$ A failure to obtain informed consent and/ or diagnose a preexisting condition are most commonly cited. Given the high risk associated with neurosurgical procedures, and the increasing frequency with which brain aneurysms are being detected, ${ }^{1,5}$ we sought to better characterize the distribution, causes, and nature of malpractice litigation related to the management of these lesions across a 30 -year period in the US.

\section{Patient Demographic Data and Geographic Distribution of Cases}

Given the increased prevalence of intracranial aneurysms among the elderly and a reported 3:1 female-to-male predominance, patient demographic data in the present study resemble current epidemiological data in the literature. ${ }^{5}$ Geographically, the malpractice cases were most commonly cited in California, New York, and Florida, in descending order. The same 3 states were found to have the greatest number of actively licensed physicians, suggesting that the number of malpractice claims may, to some degree, be a function of the number of practicing doctors within a geographical region. However, Washington was found to have the greatest number of cases per actively licensed physicians in the state. Therefore the relationship between geographical location and number of claims is potentially confounded by other factors, including patient demographic data, the relative level of education of the patients, and the number of brain aneurysms treated within each of these states. ${ }^{24}$

Interestingly, of the 26 states that have passed tort reform laws that limit payments for noneconomic damages ${ }^{2}$ (i.e., pain, suffering, loss of consortium), only 10 (39\%) were found to have malpractice cases related to the management of brain aneurysms. Monetary caps, which can de-incentivize the pursuit of compensatory payments, may serve as a deterrent in certain cases to patients and/ or plaintiffs and their legal representatives from pursuing malpractice claims or taking undue advantage of the legal system. In Texas, for example, the number of malpractice claims declined by nearly $75 \%$ over an 8 -year period following legislation passed in 2003, which limited payouts for noneconomic damages incurred in patients. ${ }^{3}$ Whether these effects are echoed in other states remains to be determined.

\section{Type of Malpractice Alleged and Defendants' Co-Specialties}

Whereas prior studies assessing the reasons for malpractice litigation have found that a perceived lack of informed consent is an important contributor, we found that only $3(4.5 \%)$ of the cases cited this as a factor. A failure to diagnose and/or to treat an existing medical condition was most commonly referenced in these cases. A very small percentage of brain aneurysms will rupture, leading to potentially fatal subarachnoid hemorrhage, with an estimated incidence of 80 cases per 32,000 unruptured aneurysms. ${ }^{19}$ This, however, is associated with a fatality rate of $25 \%-50 \%$, with half of the survivors suffering from severe neurological complications and disabilities thereaf-

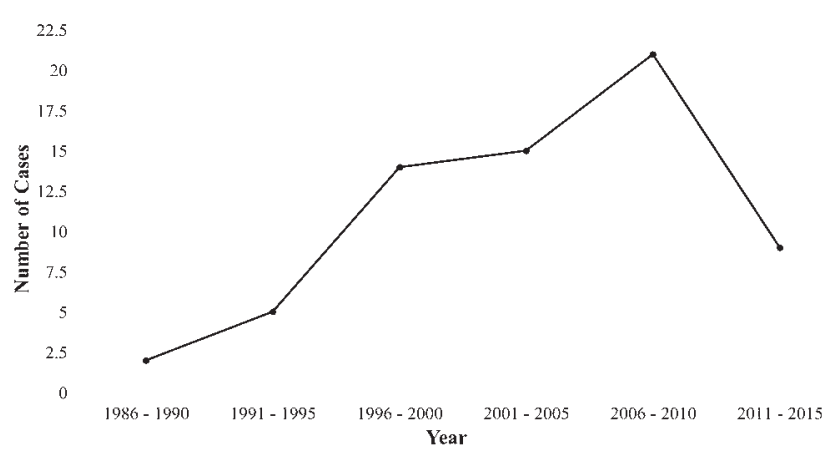

FIG. 4. Graph illustrating the number of malpractice cases relevant to the search criterion, over 5-year intervals, across a 30 -year time span.

ter. ${ }^{22}$ Prompt detection and treatment of these aneurysms is essential.

Communication between different physicians and allied health practitioners involved in the continuum of care is critical in these cases. These specialists can include primary care physicians, emergency room physicians, radiologists, nursing staff members, neurologists, and neurosurgeons. Our study revealed that only $6.7 \%$ of all defendants were neurosurgeons. Procedural error was commonly cited as the basis for litigation against these physicians. Several cases cited laceration of an artery during an endovascular procedure as the basis for the claim. Given the recent adoption of endovascular techniques in neurosurgery, operator skill, experience, and training may influence the number of adverse events in these procedures, although this must be prospectively addressed. On the other hand, internal and family medicine practitioners as well as emergency room physicians accounted for $10 \%$ of all defendants. Although these specialists are not typically involved in the surgical or endovascular treatment of cerebral aneurysms, they play an important role in the diagnosis and triage of symptomatic patients. An overwhelming majority of the patients from the cases in our study initially presented with severe headaches, nausea, and/or vomiting. The differential diagnosis of a brain aneurysm should be considered by primary care physicians and emergency room physicians in patients presenting with this symptomatology.

Equally important to consider is the role of radiologists-CT and MRI studies are used frequently to detect brain aneurysms in patients with associated risk factors. Evaluation of these images preempts and often supplants the use of digital subtraction angiography to characterize the geometry of the lesions. Given that the size and shape (e.g., daughter sac) of an aneurysm is correlated with an increased rate of rupture, ${ }^{10}$ early detection is critical. A failure to diagnose and a failure to treat were the 2 most commonly alleged causes of malpractice. Treatment of these lesions is founded upon an accurate and timely diagnosis. In that regard, our study revealed that in addition to treating neurosurgeons, neurologists, and interventional radiologists, the role that other medical practitioners play in the continuum of care for these patients, especially at the level of detection, is important to consider.

\section{Jury Verdicts and Payments}

The jury found for the plaintiff in a significant num- 
ber of cases in our analysis. This was typically associated with large award payments, the highest of which totaled $\$ 43,000,000$. This is in contrast to what has been reported in the otolaryngological literature,${ }^{16}$ where the verdict went to the defendant physician in a majority of the cases. These verdicts and correspondingly large award payouts may be a result of the severity of the pathologies and debilitating disabilities associated with brain aneurysms. Of note, an analysis in 2014 of medical malpractice payouts taken from the National Practitioner Data Bank found that the severity of the alleged outcome correlated with payment amount. ${ }^{7}$ Brain damage and quadriplegia resulted in the highest payouts, with permanent, significant injuries following closely after. Accordingly, in the patients in whom an aneurysm ruptured, death, brain damage, hemi- or quadriplegia, visual deficits, and severe gait disturbances were common.

Payouts also vary by geographic location, and by an individual state's tort reform legislation. The 2 largest payouts in our study were $\$ 43,000,000$ and $\$ 41,444,531$. These were both awarded in cases decided in New York. Recent data found that New York had annual malpractice payouts totaling more than $\$ 300,000,000$, and that it had the largest per capita payout of all states in the country. Additionally, a cap on noneconomic damages has not been instituted here (Fig. 2). Future analyses that consider the severity of a patient's condition postintervention, the resultant malpractice payout, and the state in which the trial was held may help to better elucidate these trends.

Of the cases that were settled, the mean payout was nearly 5 times less (Table 1). Interestingly, an analysis in 2013 found that of the medical malpractice cases that resulted in a payout, $96 \%$ were decided via settlement. ${ }^{6}$ Our study found that of the $\$ 239,461,720$ awarded to plaintiffs across all cases (excluding any mixed verdicts), $87.9 \%$ had been decided by judgment. Only $12.1 \%$ had been decided by settlement. Given the prolonged period of time for which medical malpractice cases can extend (an average of approximately 19 months), ${ }^{8}$ and the unusually large percentage of cases decided in the plaintiff's favor in our study, settling out of court may offer a method by which to bypass the lengthy and costly legal process. This is, however, partially dependent on the plaintiff's and the defendant's reservation prices (the maximum amount of money a defendant is willing to give up and the minimum amount a plaintiff demands) being reconcilable with one another and on the relative strength of each party's legal position. ${ }^{21}$

\section{Chronological Distribution of Cases}

The documented increase of the use of CT and MRI studies in hospitals across the US in the 1980s, and the resultant increase in the rate at which aneurysms are being detected, ${ }^{5}$ may explain the increase in the number of reported malpractice cases from 1986 to 2010. Whether the consequent decrease in the number of cases from 2011 onward is due to the effects of tort reform legislation is a possibility that should be considered.

\section{Limitations of the Study}

Case files on the WestLaw database are often heterogeneous, and access to local cases as well as cases that were dismissed prior to trial is limited. Settled cases that did not progress to trial are unavailable on the database. This is important to consider because up to $85 \%$ of surgical malpractice cases are resolved prior to trial, either because the plaintiff drops the suit, a judge orders it dismissed, or the parties settle. ${ }^{18}$ Apportionment of fault in individual verdicts is not available. Use of the database in conjunction with other legal databases including LexisNexis (Reed Elsevier Group) may allow for a more thorough analysis. Finally, there are a number of factors that can influence a plaintiff's decision to file a claim, including his or her relationship with a physician or hospital or the perceived financial incentives for going to trial, which should be considered.

\section{Conclusions}

Neurosurgery remains a high-risk specialty in regard to malpractice litigation. An analysis of malpractice claims related to the management of brain aneurysms found that plaintiffs were likely to point to a failure to diagnose and/ or a failure to treat as the basis for their claim. Interestingly, neurosurgeons represented a fraction of the total number of defendants, suggesting the importance of the role of other specialists in the management of patients with brain aneurysms. Of note, our study revealed that the jury returned a verdict in the plaintiff's favor in a significant number of cases, resulting in large payouts. Of the cases that were settled out of court, the payments were dramatically reduced. Whether the adoption of endovascular techniques in the treatment of brain aneurysms affects the incidence and nature of malpractice claims remains to be seen. Future studies, in which these types of cases are evaluated within the context of cerebrovascular neurosurgery or even neurosurgery, might provide a more holistic glimpse into the nature of these lawsuits.

\section{Acknowledgments}

Dr. John C. P. Goldberg, professor of law and tort law expert (Harvard Law School, Cambridge, MA), critically reviewed and revised this manuscript prior to its submission.

\section{References}

1. Ajiboye N, Chalouhi N, Starke RM, Zanaty M, Bell R: Unruptured cerebral aneurysms: evaluation and management. ScientificWorldJournal 2015:954954, 2015

2. American Tort Reform Association: Noneconomic damages reform. ATRA.org (http://www.atra.org/issues/noneconomicdamages-reform) [Accessed October 13, 2016]

3. Associated Press: 10 years of tort reform in Texas bring fewer suits, lower payouts. Insurance Journal. (http://www. insurancejournal.com/news/southcentral/2013/09/03/303718. htm) [Accessed October 13, 2016]

4. Baltic S, Baltic S: Tort reform. While some states have taken action to cap damages, fear of litigation still drives defensive medicine. Med Econ 90:20-22, 24-26, 2013

5. Brown RD Jr, Broderick JP: Unruptured intracranial aneurysms: epidemiology, natural history, management options, and familial screening. Lancet Neurol 13:393-404, 2014

6. Gower J: 2014 medical malpractice payout analysis. Diederich Healthcare. (http://www.diederichhealthcare. com/the-standard/2014-medical-malpractice-payoutanalysis/) [Accessed October 13, 2016] 
7. Gower J: 2015 medical malpractice payout analysis. Diederich Healthcare. (http://www.diederichhealthcare. $\mathrm{com} /$ the-standard/2015-medical-malpractice-payoutanalysis/) [Accessed October 13, 2016]

8. Jena AB, Chandra A, Lakdawalla D, Seabury S: Outcomes of medical malpractice litigation against US physicians. Arch Intern Med 172:892-894, 2012

9. Jena AB, Seabury S, Lakdawalla D, Chandra A: Malpractice risk according to physician specialty. $\mathbf{N}$ Engl J Med 365:629-636, 2011

10. Ogilvy CS, Chua MH, Fusco MR, Griessenauer CJ, Harrigan MR, Sonig A, et al: Validation of a system to predict recanalization after endovascular treatment of intracranial aneurysms. Neurosurgery 77:168-174, 2015

11. Packer-Tursman J: The defensive medicine balancing act. Med Econ 92:43, 45-48, 2015

12. Sage WM: Medical malpractice reform: when is it about money? Why is it about time? JAMA 312:2103-2105, 2014

13. Smith TR, Habib A, Rosenow JM, Nahed BV, Babu MA, Cybulski G, et al: Defensive medicine in neurosurgery: does state-level liability risk matter? Neurosurgery 76:105-114, 2015

14. Smith TR, Hulou MM, Yan SC, Cote DJ, Nahed BV, Babu MA, et al: Defensive medicine in neurosurgery: the Canadian experience. J Neurosurg 124:1524-1530, 2016

15. Studdert DM, Mello MM, Sage WM, DesRoches CM, Peugh $\mathrm{J}$, Zapert K, et al: Defensive medicine among high-risk specialist physicians in a volatile malpractice environment. JAMA 293:2609-2617, 2005

16. Svider PF, Husain Q, Kovalerchik O, Mauro AC, Setzen M, Baredes S, et al: Determining legal responsibility in otolaryngology: a review of 44 trials since 2008. Am J Otolaryngol 34:699-705, 2013

17. Svider PF, Keeley BR, Zumba O, Mauro AC, Setzen M, Eloy JA: From the operating room to the courtroom: a comprehensive characterization of litigation related to facial plastic surgery procedures. Laryngoscope 123:1849-1853, 2013

18. Svider PF, Kovalerchik O, Mauro AC, Baredes S, Eloy JA: Legal liability in iatrogenic orbital injury. Laryngoscope 123:2099-2103, 2013

19. Thompson BG, Brown RD Jr, Amin-Hanjani S, Broderick JP, Cockroft KM, Connolly ES Jr, et al: Guidelines for the man- agement of patients with unruptured intracranial aneurysms: a guideline for healthcare professionals from the American Heart Association/American Stroke Association. Stroke 46:2368-2400, 2015

20. Thorpe KE: The medical malpractice 'crisis': recent trends and the impact of state tort reforms. Health Aff (Millwood) Suppl Web Exclusives:W4-20-W4-30, 2004

21. Van Poucke D, Buelens M: Predicting the outcome of a twoparty price negotiation: contribution of reservation price, aspiration price and opening offer. J Econ Psychol 23:67-76, 2002

22. Wardlaw JM, White PM: The detection and management of unruptured intracranial aneurysms. Brain 123:205-221, 2000

23. Whang JS, Baker SR, Patel R, Luk L, Castro A III: The causes of medical malpractice suits against radiologists in the United States. Radiology 266:548-554, 2013

24. Young A, Chaudhry H, Pei X, Halbesleben K, Polk D, Dugan M: A census of actively licensed physicians in the United States, 2014. J Med Regul 101:8-23, 2015

\section{Disclosures}

The authors report no conflict of interest concerning the materials or methods used in this study or the findings specified in this paper.

\section{Author Contributions}

Conception and design: Gupta. Acquisition of data: Gupta. Analysis and interpretation of data: Gupta, Griessenauer, Adeeb. Drafting the article: Gupta, Griessenauer. Critically revising the article: Gupta, Griessenauer, Moore, Patel. Reviewed submitted version of manuscript: Griessenauer, Moore, Adeeb, Patel. Statistical analysis: Adeeb. Administrative/technical/material support: Ogilvy, Thomas. Study supervision: Ogilvy, Thomas.

\section{Correspondence}

Raghav Gupta, Division of Neurosurgery, Beth Israel Deaconess Medical Center, Harvard Medical School, 110 Francis St., Ste. 3B, Boston, MA 02215. email: rgupta5@bidmc.harvard.edu. 